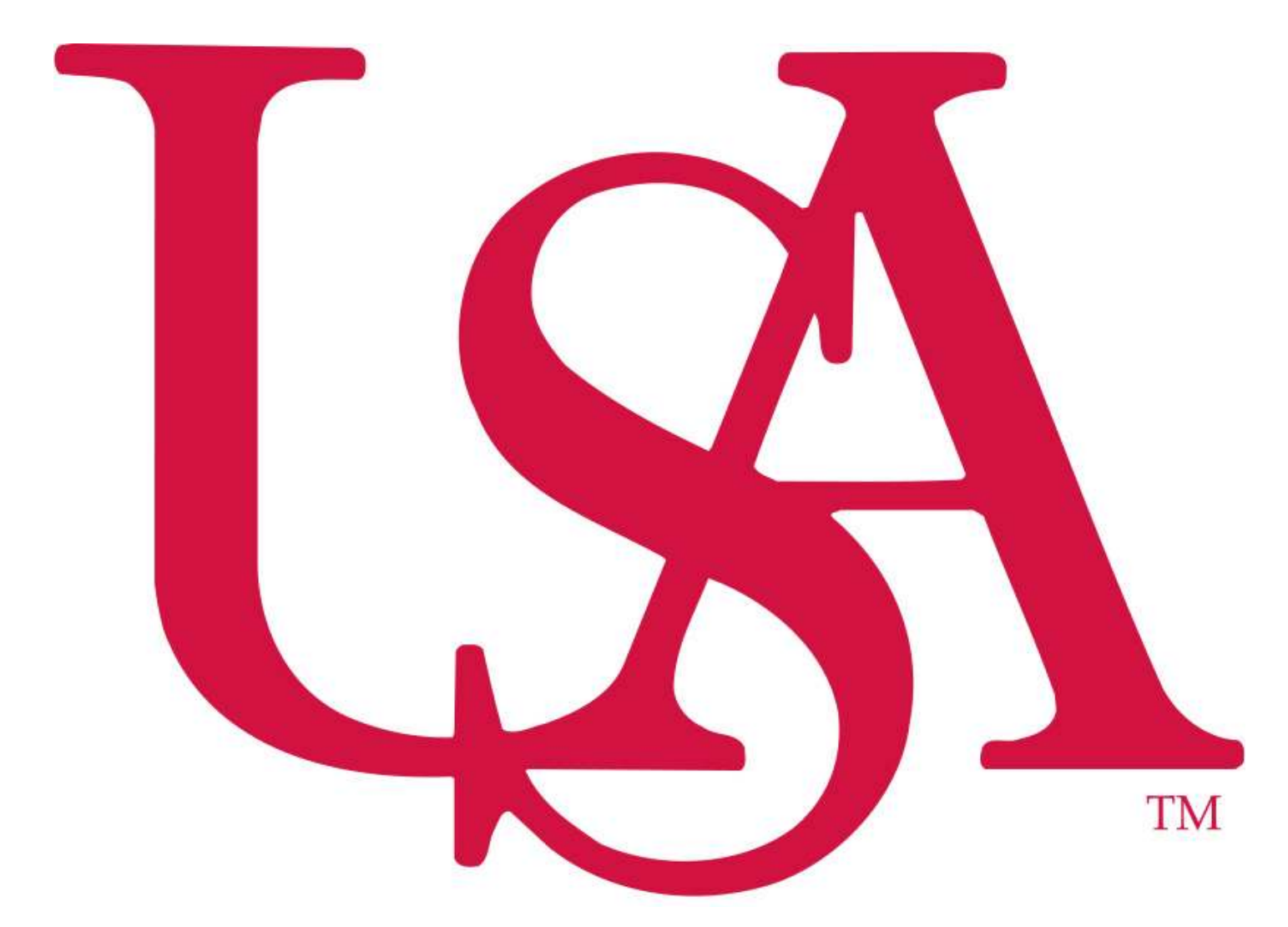

Facing the high cost of textbooks, many universities are exploring how to lower student textbook expenses. Hence the appearance of Open Education Resources (OER), Inclusive Access (IA) and other means to help students with textbook access.

Many health science libraries have been researching emerging and alternate avenues for providing textbook access to their users, including OER, IA and using LibGuides, etc.

This poster discusses how to provide "free" textbooks to health science students by using the library's existing electronic resources and resources requested by faculty.

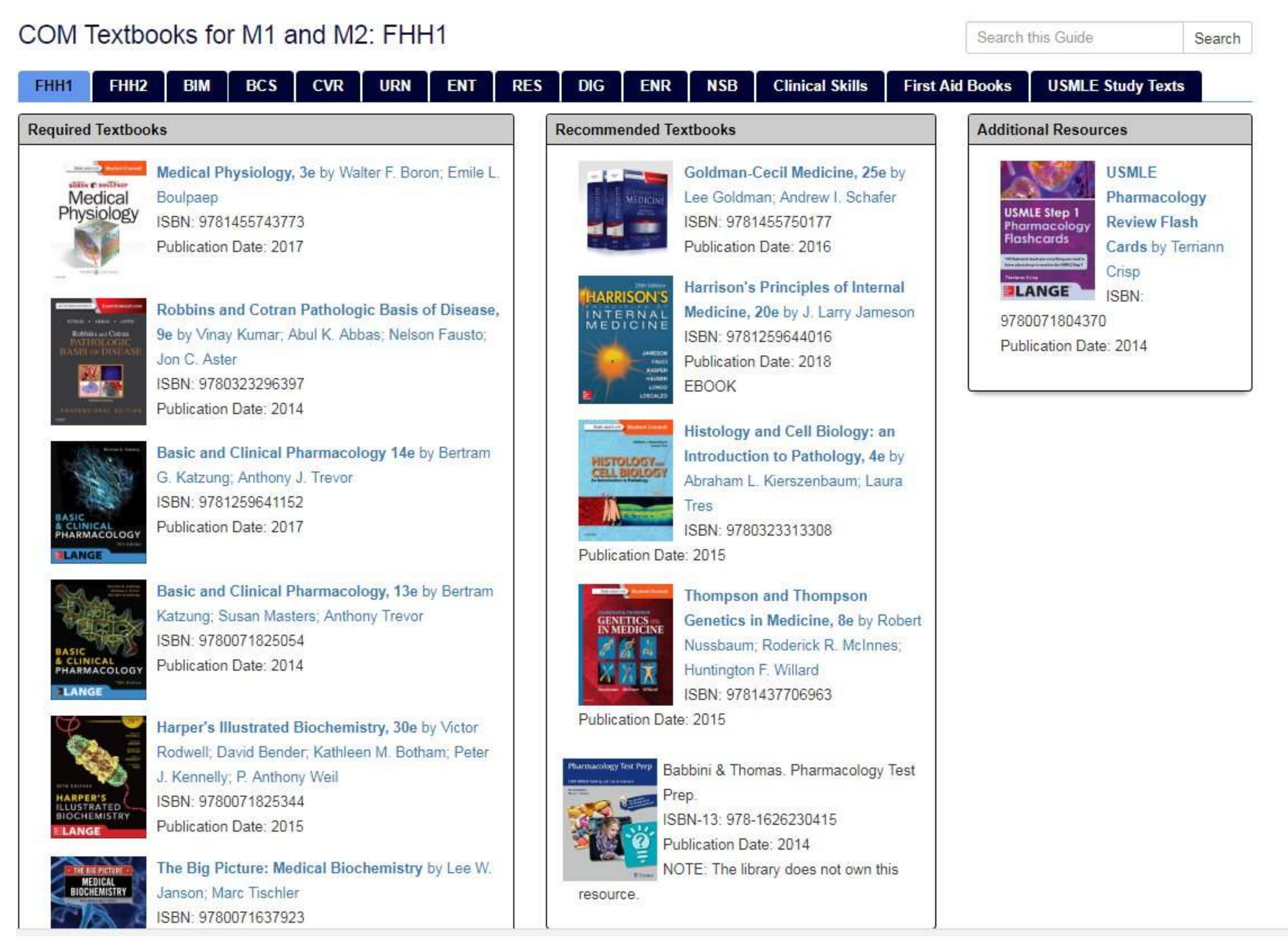

Required and recommended textbooks for $1^{\text {st }}$ and $2^{\text {nd }}$ year medical students

\title{
Exploring Avenues to Help Health Science Students with Textbook Access via the Library's Electronic Resources
}

Jie Li, Assistant Director for Collection Management Robert M. Britton, Collection Development/Electronic Resource Librarian University of South Alabama Biomedical Library

\section{Methods}

The authors use several methods to identify the best resources for users: 1. Using Doody's Core Titles, a health science book review service, and other authority lists, to identify health science books from the existing electronic resources; 2 . Working with College of Medicine Curriculum Committee and Graduate Medical Education Committee for their input on the subject guides; 3 .

Suggesting alternative books to faculty to use as textbooks; 4. Purchasing unlimited copy licenses of e-books that are available to libraries to meet faculty demand for textbooks. The textbooks are then put on LibGuides by course or subject for students.

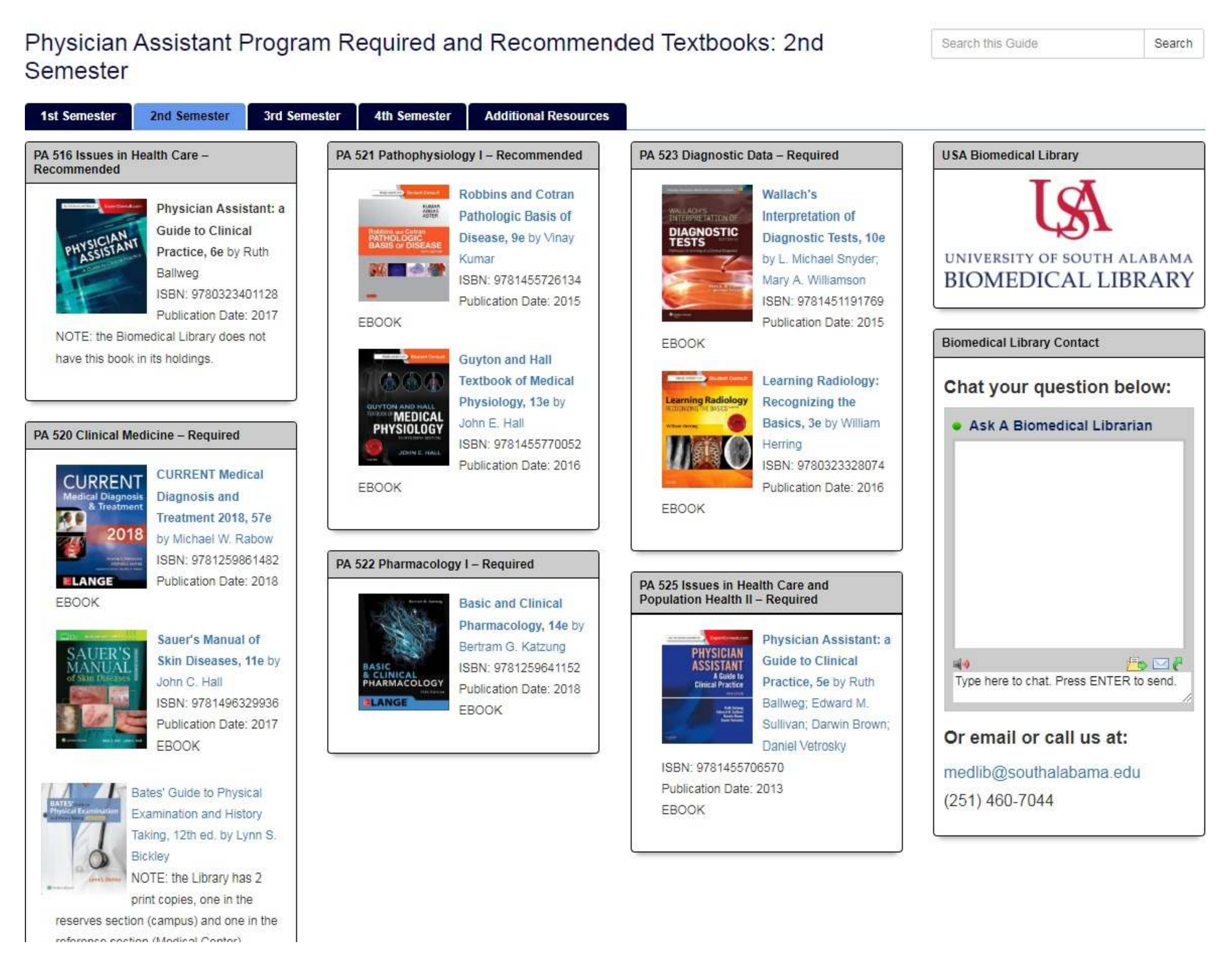

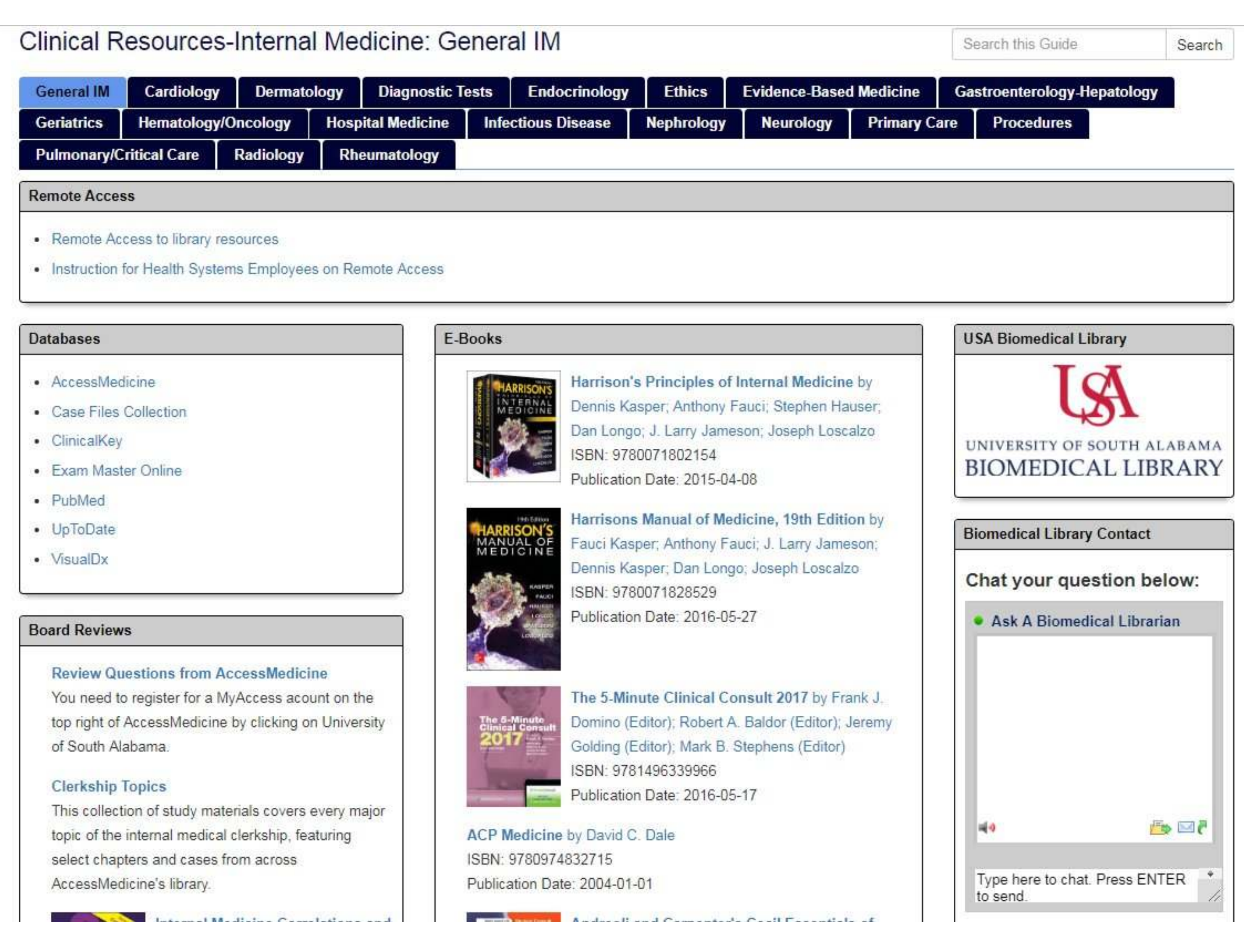

Results: 1 . Students and faculty satisfaction; 2 . Increased usage of library resources; 3. More communication and collaboration between librarians and teaching faculty.

\begin{tabular}{|l|r|r|}
\hline Year & eBook Usage & \multicolumn{2}{c}{ Percent Increase } \\
\hline 2015 & 7,458 & \\
\hline 2016 & 10,516 & $41.0 \%$ \\
\hline 2017 & 12,127 & $15.3 \%$ \\
\hline Usage statistics for ClinicalKey eBooks & $2015-2017$ & \\
\hline
\end{tabular}

Conclusion: Utilizing the best collection management practices while working closely with faculty to create quality subject guides helps address student textbook needs.

41 UNIVERITYY OF SOUTH ALABAMA 